\title{
Smart transit payment for university campus transportation using RFID card system
}

\author{
Marion Olubunmi Adebiyi ${ }^{1}$, Roseline Oluwaseun Ogundokun ${ }^{2}$, Alabo Inatimi Nathus ${ }^{3}$, \\ Emmanuel Abidemi Adeniyi ${ }^{4}$ \\ ${ }^{1,2,4}$ Department of Computer Science, Landmark University Omu Aran, Kwara State, Nigeria \\ ${ }^{1,3}$ Department of Computer Science, Covenant University Ota, Ogun State, Nigeria
}

\section{Article Info}

Article history:

Received Apr 6, 2020

Revised Mar 10, 2021

Accepted Mar 22, 2021

\section{Keywords:}

RFID card

Smart transportation

Transit payment system

Transportation business

University

\begin{abstract}
In the transportation business, we aim to be cost-efficient and effective in our customer service but with the traditional transit payment system, it is not so. Lately, transit companies all over the world are moving towards superior client service, nimbleness, receptiveness to necessities that diverge at a time scale that was absurd even two decades ago. The aim of this study was to create an electronic transit payment system that will allow for full pliability and solutions functionality that Covenant Universities and Nigerian transit companies should adopt to become more effective and efficient. We achieved this with the use of radio frequency identification (RFID) smart cards and card readers aiding a computer program that was programmed using $\mathrm{CH}$. In addition, the program was simple and not expensive to implement in order to eliminate the mismanagement of ticket funds, loiter paper in bus stations, and so on. Together all this became our payment system.
\end{abstract}

This is an open access article under the CC BY-SA license.

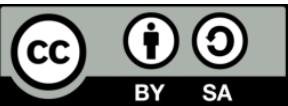

\section{Corresponding Author:}

Roseline Oluwaseun Ogundokun Department of Computer Science Landmark University

Omu Aran, Kwara State, Nigeria

Email: ogundokun.roseline@lmu.edu.ng

\section{INTRODUCTION}

Management information systems (MIS) are designed to provide information suitable for the planning, coordination and control of functional area operations within a coordination or an organization as a whole [1]. This paper deals with MIS used by transit (transportation) companies to perform their tasks at the operational and real-time management level. Worldwide, transit authorities have adopted some kind of transit management systems consisting of various resources such as: vehicle tracking; collection of operational resources such as geofences, vehicle stops and messaging facilities, individual vehicle dashboards, road builders; logistics planning and zone formation, maintenance; routine warnings and vehicle health monitoring, fuel consumption monitoring. This study features the implementation of a card-based transit payment system with the use of radio frequency identification (RFID) smart cards as the medium of payment in our management information system (RFID cards are also known as contactless cards) [2]. Those cards can process, store data and communicate through radio waves with a terminal. Contactless smart cards do not contain RFID [3]-[12] read only, but do contain a rewritable smart card chip which can be transcribed through radio waves [13], [14]. Such cards only need close proximity between the card itself and the card reader which ranges from $10 \mathrm{~cm}$ to $50 \mathrm{~cm}$ to complete a transaction, but it depends on the type of contactless card in use (there are two accepted types of contactless ISO/IEC 14443 and ISO/IEC 15693 smartcards). Contactless smart cards are frequently used in situations where transactions need to be processed instantly, 
most often in mass transit systems where a customer can complete the transaction without ever removing a wallet card [15]. Contactless smart cards were first used in Seoul, South Korea in 1995 and Hong Kong, China in 1997 for electronic ticketing. New technologies like RFID [16]-[22] give transit authorities that use proprietary payment systems an opportunity to move away from an expensive and inflexible proprietary fare systems enabling transit authorities to provide customers with great transportation services and also avoid being cheated or making losses.

Businesses in all industries operate on decreased profit margins, mostly as a result of intensified competition and higher operating costs. The demands of contemporary transit payment systems are not only cost-effectiveness but also superior customer support, agility and sensitivity to requirements that differ at a time scale that was previously unimaginable even a decade ago. The Covenant University Shuttle services department as a matter of fact does not have a computerized transit payment system in place; the system currently in place is obsolete and is not computerized. Cash is still the primary form of payment and accounts are reconciled using ticket books that are issued to passengers on boarding. It is certainly not the most efficient system that should be utilized for an organization with Covenant University's transportation requirements.

The aim of this research is to provide a transit payment system that will allow for full flexibility and solutions functionality. Although transit payment systems usually compose of a host of applications and tools, due to the scope of this study, it will only be limited to one feature, a smart card based fare collection section. The system will be able to provide a more secure and robust transit management system by implementing a system using more advanced and secure programming techniques and programming platforms, increase efficiency by standardizing and streamlining processes, reduce cost and fraud that plagues the current system, provide a more convenient way for riders to pay their fare, solve the need to serve more customers in less time, streamline processes by implementing a solution specifically tailored to organizational needs thereby improving system functionality and saving money, provide more visibility into the system to enable better management decisions, develop a cash free environment which will ensure that the transport system be a safer travelling environment and lastly saving cost by reducing fraud and theft.

Paul and Suresh [23] described a smart public transport network in which RFID and Agent Technology were applied to dynamic bus trip scheduling and an enhanced cashless payment network. This keeps track and schedule of buses along with monitoring of bus/commuter interactions with emphasis on supply and demand with the goal of showing the actual location of the buses at any given time along with the density of the buses at stops by RFID tagging.

Rohit et al. [24] proposed a universal transport billing system using RFID that can be used for the billing of different transport systems like bus, toll gate collection booth, parking systems and petrol station bill by adding automation in the existing system, the authors also added a new functionality such as SMS notification to notify the user the status of transaction when it ceases at a particular point. The system was robotics but will be better to be used for private commuters since it was universal system with multiple functionalities. Also there will be an extra chargers on the part of the customers since the system send notification through short message service (SMS).

Sunitha et al. [25] the authors incorporate web-based monitors with the automatic RFID fare collection system to collate the amount path taken bus status number of passengers' distance information. There work was able to overcomes some problems faced in bus with IoT based web-page monitor system. There system uses WiFi hot-spot or wireless network which means that the system can only work in the range of internet connectivity and render powerless when there is internet connectivity issue.

Therefore, the aim of this research is to provide a smart transit payment for University Campus transportation using RFID card system that will allow for full flexibility and solutions functionality. Although transit payment systems usually compose of a host of applications and tools, due to the scope of this research, it will only be limited to one feature, a smart card based fare collection section.

\section{RESEARCH METHOD}

The Boston massachusetts bay transit authority in the United States was visited to gather the relevant information on an existing Transit Payment System. The Covenant University Shuttle service was also visited to collect information on the visibility of the current system. Data was collected through interviews of the relevant staff and observation of the current system in use.

The .NET Framework will be used to provide the necessary API's the software will need to run in the design of the system with the use of Visual studio 2012, C\# will be the programing language for programing the system, unified modelling language (UML). RFID smart cards were purchased to be used as the fare payment cards and also an ACR 122U RFID smart card reader was purchased for the use of reading the RFID smart cards. The RFID cards were also used to provide the backend database support as it has a 
built-in memory of 16 separate blocks that can be used to store values and card holder information if needed. Figure 1 shows a Use Case for the Payroll system. The actors involved are the Payroll Administrator, management and the Employee.

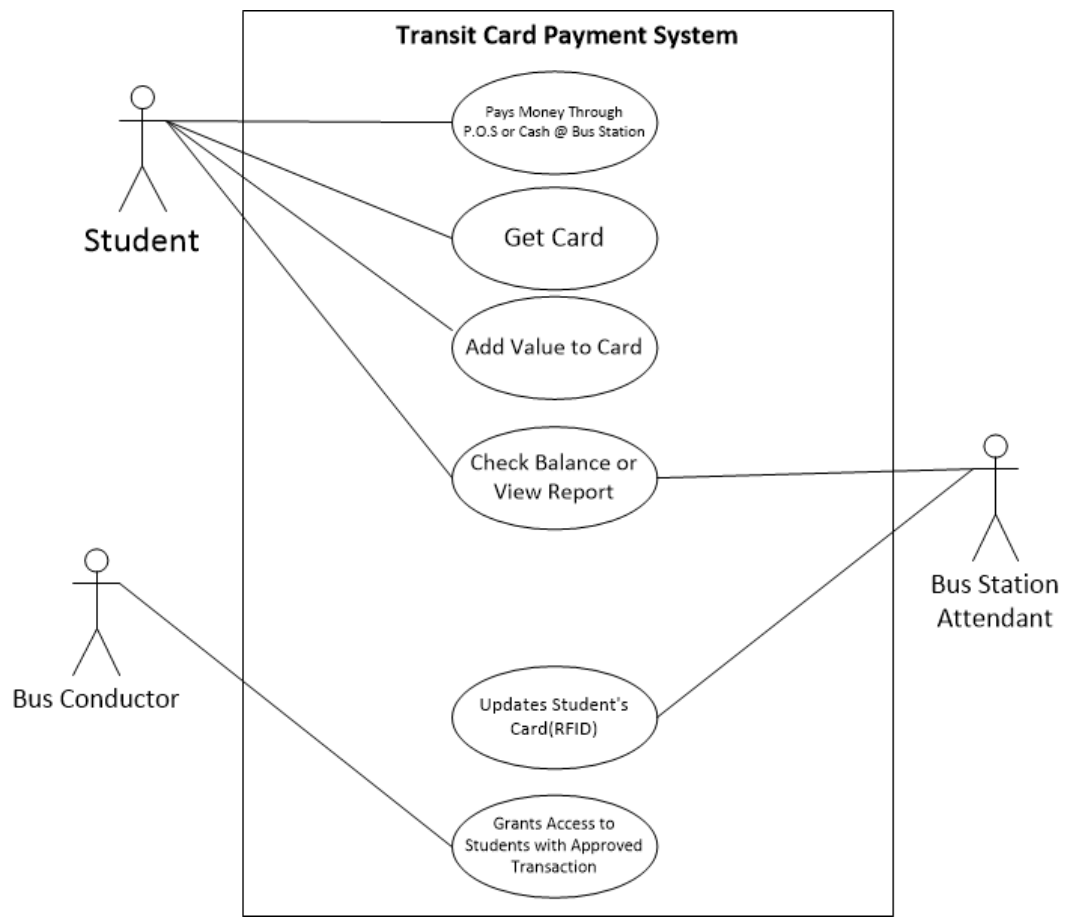

Figure 1. Use case diagram of the transportation card payment system

\subsection{Programming language used}

The choice of programming language was C\# and SQL Server 2012 was used for the back-end database support. C\# was chosen because C\# has a wide array of unique and useful features that are the best and only reason for using $\mathrm{C} \#$ in programming Microsoft $\mathrm{C} \#$ is a programming language developed to develop a wide variety of business applications operating on the .NET Framework.

\subsection{Program modules}

The Covenant University transport system has been designed to be user friendly and it is easy to navigate. The graphical user interface (GUI) is very well structured and provides a level of flexibility as to how the program modules can be accessed. This program was implemented on a modular basis; it consists basically of 4 modules such as:

- Home window (get card)

- Add value window

- Check balance

- Transaction

Each of them will be explained in detail outlining the functionality of each module and providing a screenshot showing the program module that is being discussed.

\section{RESULTS AND ANALYSIS}

\subsection{Home window (get card)}

This is the first window that the user interacts with when the system is first run as shown in Figure 2. This window shows all the available features of the system. It allows the administrator to choose the specific feature of the software he would like to use.

\subsection{Add value window}

Figure 3 shows the add value window. This window allows the administrator to add value to a rider's card through a user interface. After the financial transaction has been verified, the administrator adds 
the specified amount to the rider's card by entering the amount and clicking the add value button as shown in Figure 4.

\subsection{Check card window}

Figure 5 shows the check balance window. This window allows the administrator or rider to check the balance of a rider's card through a user interface. The rider/administrator places the card on the reader and clicks the check balance button. The balance is then displayed as shown in Figure 6.

\subsection{Transaction window/bus ride}

Transaction window is shown in Figure 7. This window is the main module that will be constantly running on all endpoints located on buses. This allows a rider to make a transaction with his card. The rider places his card on the reader upon boarding the bus and he required fare is deducted from his card and a message is shown as displayed in Figure 8. If the rider has insufficient balance, an error message is shown as displayed in Figure 9 and he can either add more value to his card or get off the bus.

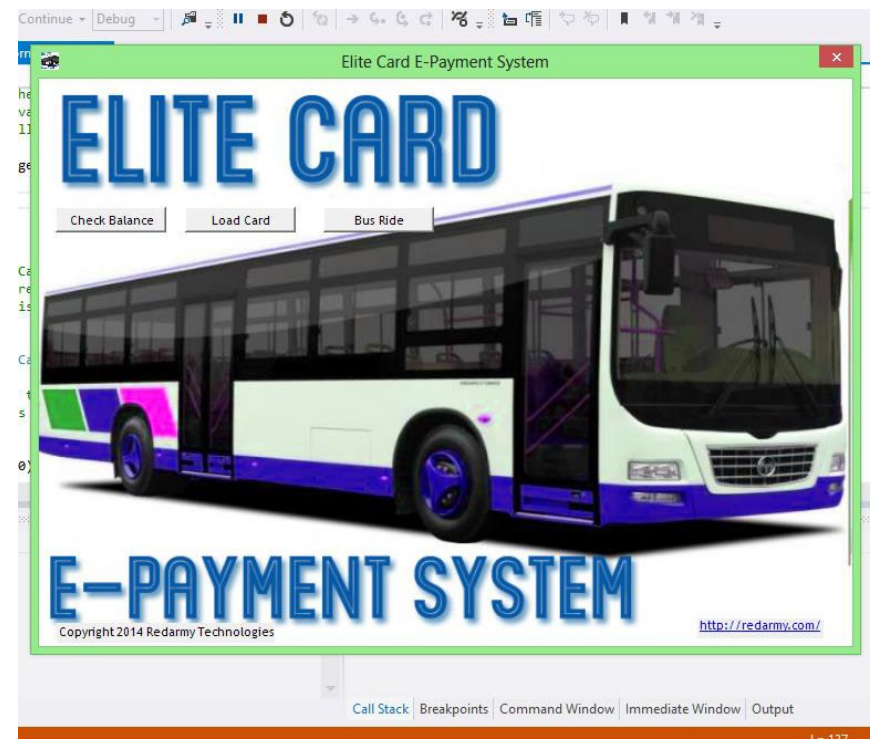

Figure 2. Home window (when the program is opened)

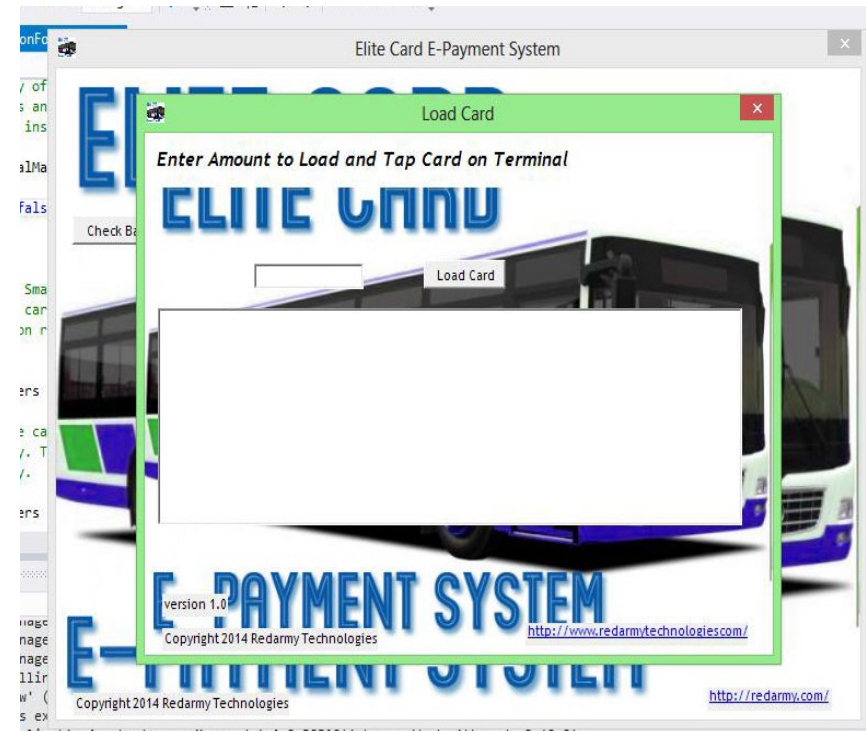

Figure 3. Add value window 


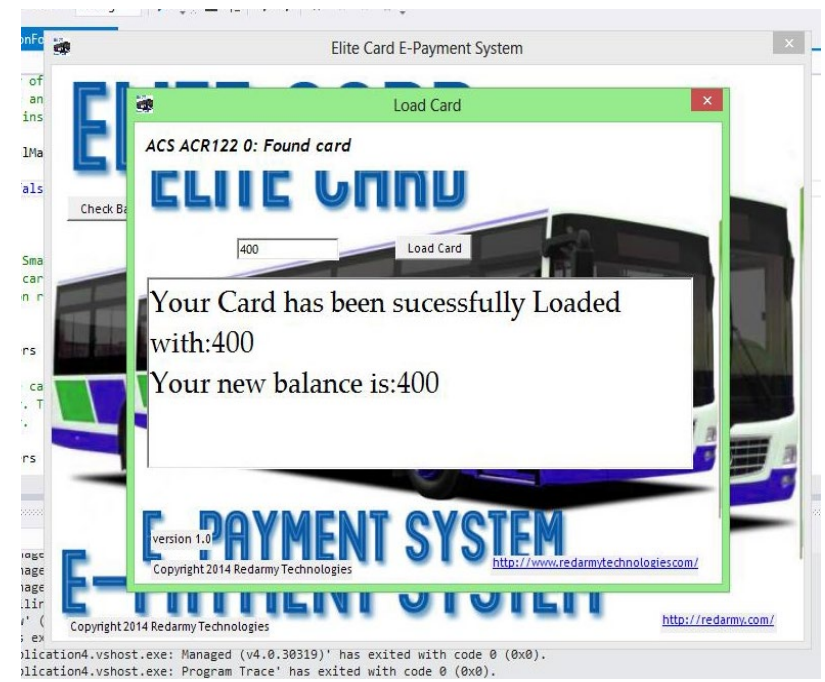

Figure 4. Add value window (when a value being added)

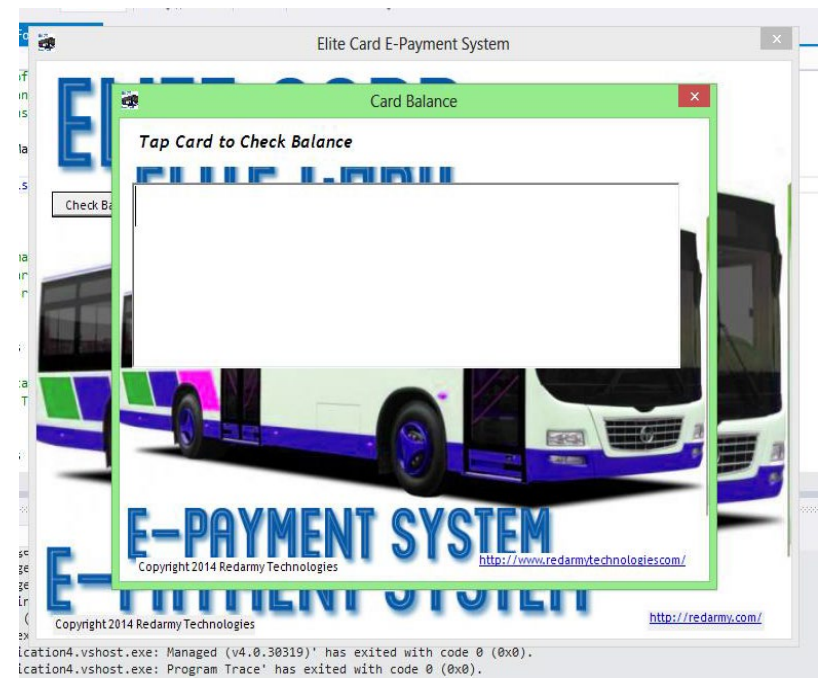

Figure 5. Check balance window

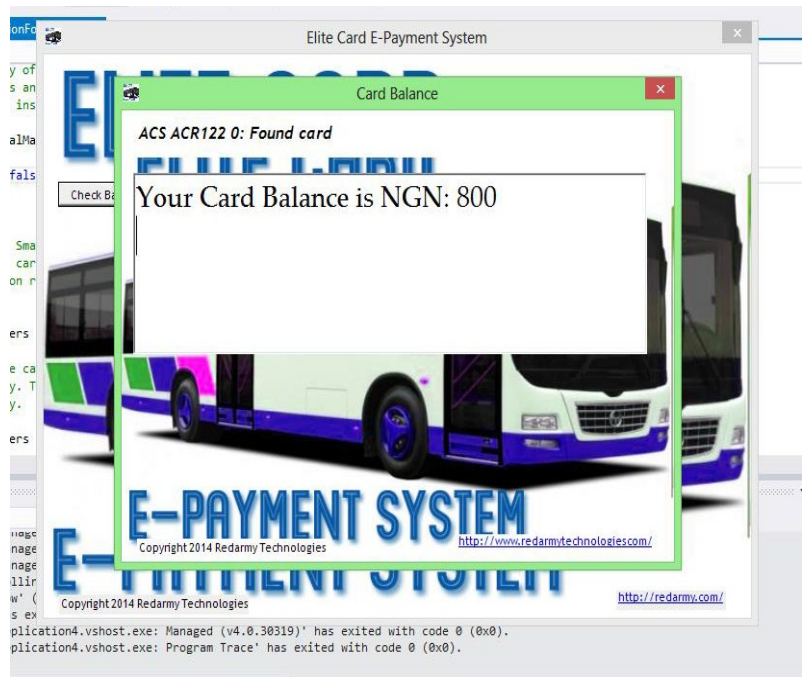

Figure 6. Check balance window (when customer is checking balance) 


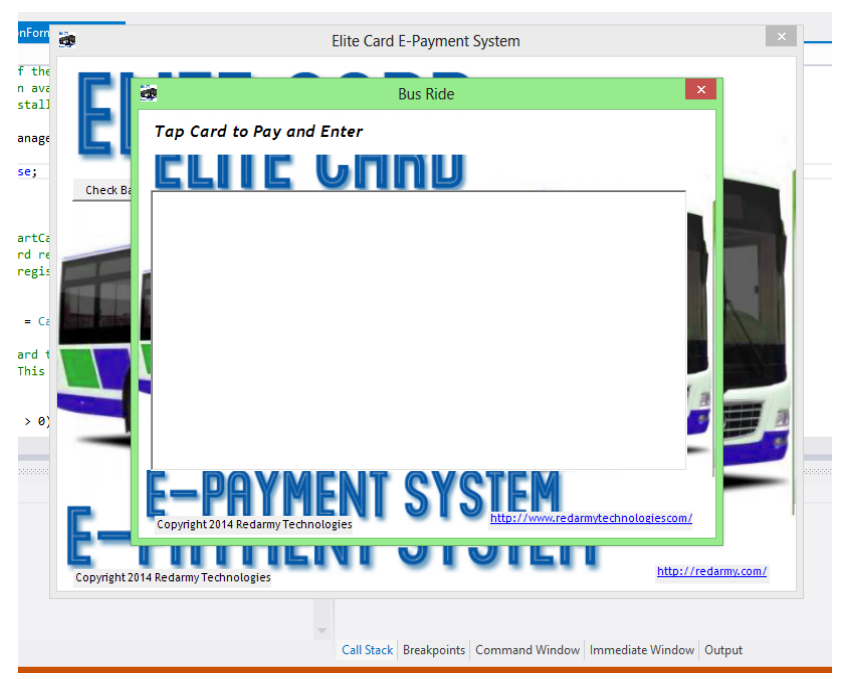

Figure 7. Transaction window

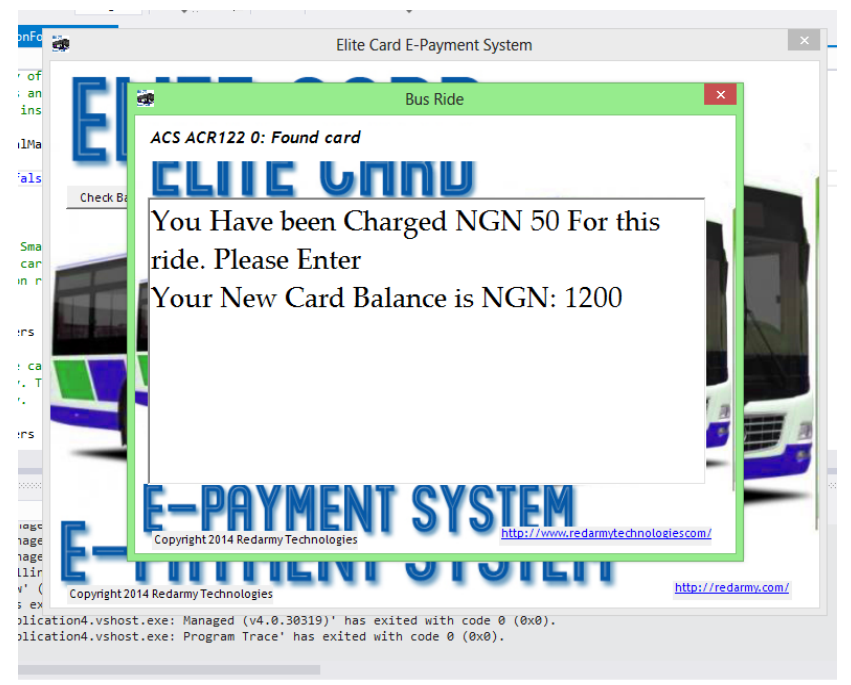

Figure 8. Transaction window (when customer is paying for a bus ride)

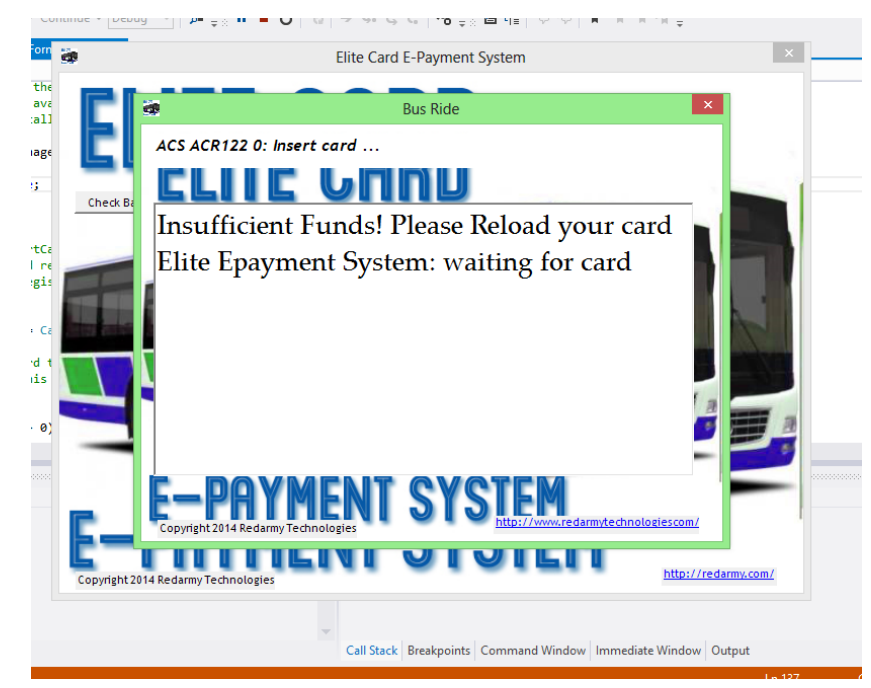

Figure 9. Transaction window (when customers balance is not enough) 


\section{CONCLUSION}

Businesses all over the world look for various ways of cutting down operational cost and increasing transaction efficiency and customer service. RFID cards in transport have proven to be not only a suitable alternative but a more efficient and effective better option for fare payments. One major fact is that RFID is a relatively new and very useful technology to a lot of people. It has been used in several areas and industries and can be used in so many more (the possibilities are endless).

\section{RECOMMENDATIONS}

The author recommends this software package to Universities' Transportation body and all other organizations that wishes to improve and adopt a more effective, efficient and modern payment system. The users of the software developed must be trained on how to use the software. That is, if there is no prior knowledge of the use of the computer exists. Lastly, a login platform is recommended so that the software can be used by only authorized personnel only.

\section{REFERENCES}

[1] Adebayo F. A., "Management Information System for Managers," Ado-Ekiti: Green Line Publishers, 2007. doi: 10.1109/ICAdLT.2013.6568465.

[2] O. A. Marion, O. O. Florence, O. A. Daramola, O. O. Roseline, and A. A. Emmanuel, "RFID-Based Human Tracking System in Tertiary Institution," Journal of Engineering and Applied Sciences, vol. 14, pp. 2345-2351, 2019.

[3] T. H. J. Chow, "U.S. Patent No. 10,515,360," Washington, DC: U.S. Patent and Trademark Office, 2019.

[4] O. Abayomi-Alli, M. Odusami, R. Chima, S. Misra, R. Ahuja, R. Damasevicius et al., "Smart Ticketing for Academic Campus Shuttle Transportation System Based on RFID," in Advances in Data Sciences, Security and Applications, pp. 237-252, 2020, doi: 10.1007/978-981-15-0372-6 18.

[5] P. D. Saunders, L. J. Peart, and B. T. Barnes, "U.S. Patent No. 7,731,086," Washington, DC: U.S. Patent and Trademark Office, 2010.

[6] A. O. Zadorozhnii, M. S. Dorosh, I. V. Bohdan, and L. K. Svetenok, "Using the agent-oriented simulation model finding route parameters in an automated public transport management system," Математичні машини $i$ системи, vol. 3, pp. 120-128, 2019. doi: 10.34121/1028-9763-2019-3-120-128.

[7] F. Simon and M. Simon, "U.S. Patent Application No. 11/257,121," 2006.

[8] R. Nishitha, S. S. Naik, V. Raksha, and U. Kulsum, "IoT Based Automatic Billing System Using Barcode Scanner by Android Device and Monitoring Unregistered Barcode by RFID," in 2019 4th International Conference on Recent Trends on Electronics, Information, Communication and Technology (RTEICT), 2019, pp. 15-20, doi: 10.1109/RTEICT46194.2019.9016698.

[9] T. J. Nipa, B. Rouhanizadeh, and S. Kermanshachi, "Utilization and Implementation of the E-Ticketing Technology to Electronically Track the Delivery of Construction Materials," 7th CSCE International Construction Specialty Conference (ICSC), 2019, pp. 297-1-297-10.

[10] S. C. Yu, "RFID implementation and benefits in libraries," The Electronic Library, vol. 25, no. 1, pp. 54-64, 2007, doi: 10.1108/02640470710729119.

[11] M. O. Adebiyi, E. E. Adeka, F. O. Oladeji, R. O. Ogundokun, M. O. Arowolo, and A. A. Adebiyi, "Evaluation of load balancing algorithms on overlappiing wireless accesspoints," Indonesian Journal of Electrical Engineering and Computer Science, vol. 21, no. 2, pp. 895-900, 2020.

[12] R. E. Urbanek, "U.S. Patent No. 10,506,398," Washington, DC: U.S. Patent and Trademark Office, 2019.

[13] Izabela L., Biljana R., and Dejan L., "Contactless payment systems based on RFID technology," MIPRO, 2010 Proceedings of the 33rd International Convention, Opatija, Croatia, 2010, pp. 30-35.

[14] M. Adebiyi, F. Oladeji, S. Onyido, D. Ori, R. O. Ogundokun, A. E. Adeniyi et al., "A 3-D model of an institutional location navigation system (NaVILOC) (a case study of covenant university)," International Journal of Civil Engineering and Technology, vol. 10, no. 1, pp. 746-756, 2019.

[15] T. J. Wiechert P., Frédéric T., and Elgar F., "A quantitative evaluation of NFC based contactless payment systems in retail," 17th European Confer-ence on Information Systems, Verona, 2009.

[16] K. Pirzadeh and M. B. Kekicheff, "U.S. Patent No. 10,454,693," Washington, DC: U.S. Patent and Trademark Office, 2019

[17] M. P. Pelletier, M. Trépanier, and C. Morency, "Smart card data use in public transit: A literature review," Transportation Research Part C: Emerging Technologies, vol. 19, no. 4, pp. 557-568, 2011, doi: 10.1016/j.trc.2010.12.003

[18] J. Y. Wong and R. L. Anderson, “U.S. Patent No. 7,748,616,” Washington, DC: U.S. Patent and Trademark Office, 2010.

[19] M. L. Hamzah, Y. Desnelita, A. A. Purwati, E. Rusilawati, R. Kasman, and F. Rizal, "A review of Near Field Communication technology in several areas," Revista ESPACIOS, vol. 40, no. 32, 2019.

[20] C. Akash et al., "RFID enabled Smart cab payments," International Journal of Advance Research, Ideas and Innovations in Technology, vol. 5, no. 5, pp. 312-316, 2019.

[21] S. Smirin, "U.S. Patent No. 10,424,002," Washington, DC: U.S. Patent and Trademark Office, 2019.

\footnotetext{
Smart transit payment for university campus transportation using RFID card... (Marion Olubunmi Adebiyi)
} 
[22] A. Fox and B. Fox, "U.S. Patent Application No. 12/557,161," 2011

[23] Paul H. and Suresh S., "Intelligent Agent Based RFID System for on Demand Bus Scheduling and Ticketing," International Journal of Future Computer and Communication, vol. 2, no. 5, Oct. 2013, doi: 10.7763/IJFCC.2013.V2.194.

[24] Rohit B., Ganesh R. K., Mayur N. T., and Govind P. Y., "Tap and Pay: A Universal Transport Billing System Using RFID Smart Card," International Journal of Advanced Research in Computer Engineering \& Technology (IJARCET), vol. 4, no. 4, Apr. 2015.

[25] Sunitha A., Sangeetha G., and VidhyaJanani J., "Automatic Bus Fare Collection System Using RFID," International Journal of Advanced Research in Computer Engineering \& Technology (IJARCET), vol. 6, no. 3, Mar. 2017.

\section{BIOGRAPHIES OF AUTHORS}

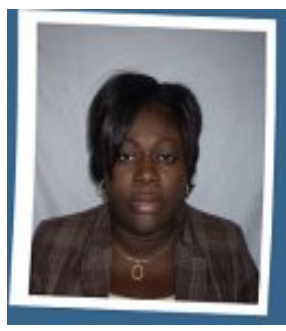

Marion Olubunmi Adebiyi is a Senior Lecturer at Covenant University Ota Ogun State in the Department of Computer \& Information Sciences. She had obtained NCE (Mathematics/ Physics, 1995), B. Sc. (Computer Science, 2000), M. Sc. and P. hD also in Computer Science (Bioinformatics), 2008 and 2014 consecutively. Her research interests include Anti-malaria drugs/ insecticide resistance mechanism discovery, organism's inter-pathways analysis, developing pipeline for high throughput data analysis and 3D protein structure and function prediction. She has published several articles in learned journals and chapters in books. She is a member of Computer Professionals (CPN), Nigeria Computer Society (NCS) and Institute of Electrical and Electronics Engineers (MIEEE) and International/African Society for Computational Biology/and Bioinformatics (ISCB/ASBCB).

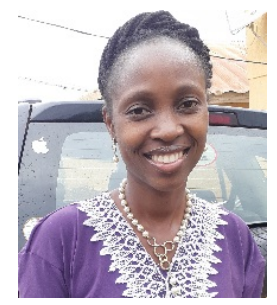

Roseline Oluwaseun Ogundokun is a Lecturer at the Department of Computer Science, College of Pure and Applied Sciences, Landmark University, Omu Aran, Kwara State, Nigeria, she holds Bachelor of Science in Management Information System from Covenant University, Ota; Master of Science in Computer Science from the University of Ilorin, Ilorin; Post Graduate Diploma in Education (PGDE) from the National Teachers' Institute (NTI), Kaduna and; currently a PhD student in the Department of Computer Science, University of Ilorin, Ilorin. Her research interests include Steganography and Cryptography, Information Security, Artificial Intelligence, Data Mining, Information Science and Human Computer Interaction.

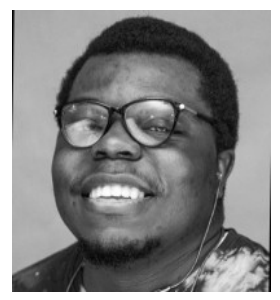

Nathus Inatimi is a graduate from Covenant University Ota, Ogun State. He is a Creative Professional with a wide range of skills from Graphic Design, Branding, Animation, character design, illustration, Video Editing, Photography \& Motion graphics for broadcast, Documentaries, commercials and advertising. I can adapt to a variety of styles be it corporate, classic, modern through to animated children's TV.

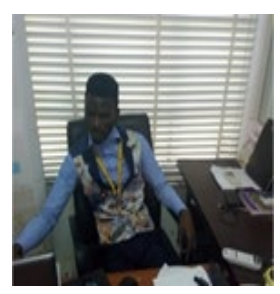

Abidemi Emmanuel Adeniyi is a Staff in the Department of Computer Science, College of Pure and Applied Sciences, Landmark University, Omu-Aran, Nigeria. He received Bachelor of Science in Computer Science from Ladoke Akintola University of Technology, Ogbomosho. His area of research includes Computer Security, Data Mining. 